Article

\title{
Preparation, Characterization and Application of a Low Water-Sensitive Artemisia sphaerocephala Krasch. Gum Intelligent Film Incorporated with Anionic Cellulose Nanofiber as a Reinforcing Component
}

\author{
Tieqiang Liang and Lijuan Wang * \\ Key Laboratory of Bio-based Materials Science and Technology of Ministry of Education, Northeast Forestry \\ University, Harbin 150040, China; tie_qiang@163.com \\ * Correspondence: donglinwlj@163.com
}

Received: 16 December 2019; Accepted: 17 January 2020; Published: 20 January 2020

check for updates

\begin{abstract}
A low-water-sensitive Artemisia sphaerocephala Krasch. gum (ASKG) based intelligent film was developed. Red cabbage extracts (RCE) was selected as a natural $\mathrm{pH}$-sensitive indicator, and anionic cellulose nanofiber (ACNF) was added as a hydrophobic and locking host. The zeta potential, rheology, Fourier-transform infrared spectroscopy, X-ray diffractometry, and release results indicated that the RCE was locked by the ACNF via electrostatic interactions, moreover, broke the original complicated network and ordered arrangement of polymer molecules in the developed intelligent films. RCE addition decreased the tensile strength, oxygen, and water vapor barrier properties and light transmission of the developed intelligent films, while increasing the elongation at break. The films could respond to buffer solutions and $\mathrm{NH}_{3}$ through different color changes. The developed intelligent film was hydrophobic, which could precisely detect the freshwater shrimp freshness in real time via color changes, which indicated that the films have potential in intelligent packaging and gas-sensing label fields.
\end{abstract}

Keywords: Artemisia sphaerocephala Krasch. gum; anionic cellulose nanofiber; red cabbage extracts; $\mathrm{pH}$-sensing film; low water-sensitivity

\section{Introduction}

Biomass packaging materials have been extensively investigated to replace synthetic plastics, because of their low cost, easy processability, non-toxicity, and biodegradability, as awareness of environmental protection and food safety has increased [1]. In recent years, commercial intelligent labels or films, such as the Timestrip ${ }^{\circledR}, 3 \mathrm{M}^{\mathrm{TM}}{ }^{\mathrm{M}}$ MonitorMark ${ }^{\mathrm{TM}}$, CheckPoint $^{\circledR}$, and Ageless Eye ${ }^{\circledR}$, appear in our daily lives [2]. However, the raw materials and indicators that are used are organic synthetic substances or heavy metals, which can harm the ecosystem and people's health, and pollute packaged food. Naturally degradable and edible intelligent films or labels have received extensive attention from researchers to resolve this problem. In recent years, polysaccharides, such as gelatin [3], chitosan [4], gellan gum [5], and starch [6] based intelligent films, have been investigated to detect seafood and meat freshness and they showed good detecting effects.

Synthetic indicators, such as methylene blue [7], bromocresol green [8], and chlorophenol red [9], were used first in intelligent packaging films. However, these indicators can pollute packaged food and may pose a harmful risk to the ecosystem and people's health [10]. To resolve those issues, natural indicators, such as curcumin [11-13], anthocyanins from black carrot [14], red cabbage [15,16], purple-fleshed sweet potato [17], and roselle [18], have been used to replace synthetic indicators in edible intelligent packaging films according to recent reports [19], because they are non-toxic [20] and 
can change color in different $\mathrm{pH}$ conditions [21]. Among them, red cabbage has been extensively used as a raw material because of its wide range of sources and low cost. Red cabbage extracts (RCE) operate over a wide spectrum at different $\mathrm{pHs}$ [22].

In our previous work, a series of intelligent films was developed, in which Artemisia sphaerocephala Krasch. gum (ASKG) was selected as a substrate [23-25]. The ASKG was a suitable film-forming material for intelligent food packaging films, however, the developed intelligent films showed a high water-sensitivity, because of the high hydrophilic property of all film-forming materials and extracts, which limits their practical application. This defect also exists in other similar films [26-28].

To resolve this defect, some scholars have selected nano-crystalline cellulose (NCC), cellulose nanofiber (CNF), or their derivatives as a hydrophobic material to reduce the film's water sensitivity, because they are green, sustainable, and eco-friendly [28-32]. Among them, anionic cellulose nanofiber (ACNF) is a nanosized flexible fibril (5-50 $\mathrm{nm}$ width and micron-scale length) with negative charge, which could disperse evenly in water $[33,34]$. ACNF has been extensively investigated, because of its high crystallinity, dispersibility, desirable environmental friendliness, and reactivity [34-36]. No report exists regarding the use of ACNF in ASKG-based films.

In this work, RCE was extracted as a natural indicator and ACNF was used as a locking and reducing water-sensitive compound. A high-sensitive intelligent film with a low water sensitivity based on ASKG was prepared. The rheology and zeta potential of every film-forming solution was determined to investigate its film-forming property and the interactions between the ACNF and RCE. The structural, morphological, mechanical, barrier, optical, thermal, and hydrophobic properties of the developed films were also characterized. The locking effects between the ACNF and RCE were evaluated through release test, the chroma-response of the developed intelligent films in solutions with different $\mathrm{pH}$ of 3.0-10.0, and a $\mathrm{NH}_{3}$ atmosphere under different humidities (33\%, 75\%, and 90\%) was also observed. An industrial production was developed and used to detect the freshwater shrimp freshness in real time, and the relationship of the response characteristics between them was also constructed to assess the practical application of the developed intelligent film.

\section{Materials and Methods}

\subsection{Materials and Regents}

ASKG was obtained from Zhengzhou Yuhe Food Additive Co., Ltd. (Zhengzhou, China). ACNF (width of $35 \mathrm{~nm}$, length $>1 \mu \mathrm{m}$, viscosity of $355 \mathrm{MPa} \cdot \mathrm{s}$ ) was obtained from Chemkey Advanced Materials Technology Co., Ltd. (Shanghai, China). Edible sodium paraben was obtained from Jingrun Bio-Tech. Co., Ltd. (Shenzhen, China). Analytical glycerol was obtained from Kemiou Chemical Reagent Co., Ltd. (Tianjin, China). Red cabbage was obtained from Songlei Supermarket (Harbin, China). Buffer solutions ( $\mathrm{pH}$ 3.0-10.0) were obtained from Beijing Wanjia Shouhua Biotechnology Co., Ltd. (Beijing, China).

\subsection{Experimental Methods}

\subsubsection{Extraction and Quantification of RCE}

RCE was extracted, according to the literature [25], $50 \mathrm{~g}$ of red cabbage powder and $1 \mathrm{~L} \mathrm{of} 50 \%$ $(v / v)$ ethanol solution were mixed and then treated under ultrasound of $540 \mathrm{~W}$ for $1 \mathrm{~h}$ at $50{ }^{\circ} \mathrm{C}$, then, filtered by using Buchner funnel to obtain the RCE solution, in which the anthocyanin content was $0.4717 \mathrm{mg} / \mathrm{mL}$, according to the literature through a $\mathrm{pH}$-differential method [37], and the solid content of RCE solution was $43.77 \mathrm{~g} / \mathrm{L}$ through a constant-mass method.

\subsubsection{Preparation of ASKG/ACNF/RCE Intelligent Films}

The preparation method from our previous works was used with some modifications [23-25]. The optimal mass ratio of ASKG and ACNF was 19:1 (total mass was $6 \mathrm{~g}$ ), according to preliminary 
experiments. Based on the optimal mass ratio, $6 \mathrm{~g}$ of ASKG and ACNF was dispersed in $600 \mathrm{~mL}$ of distilled water and then heated for $30 \mathrm{~min}$ at $60^{\circ} \mathrm{C}$ with constant stirring at $800 \mathrm{rpm}$. Subsequently, $40 \%$ (weight ratio, ACNF and ASKG basis) glycerol and 0-15\% (weight ratio, ACNF, ASKG and glycerol basis) RCE was mixed in and then stirred for a further $20 \mathrm{~min}$. The developed films were obtained through casting method by using an acrylic resin plate $(26 \mathrm{~cm} \times 26 \mathrm{~cm} \times 4 \mathrm{~cm})$ after $50 \mathrm{~h}$ at $60{ }^{\circ} \mathrm{C}$ in a drying box and recorded as AFR0, AFR5, AFR10, and AFR15.

\subsubsection{Preparation of Intelligent Films to Detect Freshwater Shrimp Freshness}

The intelligent film preparation (AFR-10P) to detect the freshwater shrimp freshness was as follows.

According to Section 2.2.2, $6 \mathrm{~g}$ of ASKG and ACNF were dispersed in distilled water and then heated for $30 \mathrm{~min}$ at $60^{\circ} \mathrm{C}$ with constant stirring at $800 \mathrm{rpm}$. Subsequently, $40 \%$ glycerol and $7.0 \%$ RCE were added and stirred for a further $20 \mathrm{~min}$. Thereafter, $0.05 \%$ sodium paraben (a food preservative) was added and stirred for a further $20 \mathrm{~min}$ according to Chinese National Standard GB 2760. The developed films were obtained through casting after $60 \mathrm{~h}$ at $50^{\circ} \mathrm{C}$ in a drying box and recorded as AFR-10P.

\subsection{Characterization}

\subsubsection{Zeta Potential Changes of Solutions}

According to our previous report, $1 \mathrm{~mL}$ of samples was added to a specific cell and then tested at $25^{\circ} \mathrm{C}$ on a Zetasizer Nano ZS (under He-Ne laser at $90^{\circ}$ scattering angle, Malvern, Worcestershire, UK) [25].

\subsubsection{Rheological Analysis of Solutions}

The rheology test was conducted according to the literature [25]. The shear rate ranged from 0.1 to $100 \mathrm{~s}^{-1}$ and the test temperature was $25^{\circ} \mathrm{C}$.

The flow behavior was assessed by using a Cross model with the following equation:

$$
\eta=\eta_{\infty}+\left(\eta_{0}-\eta_{\infty}\right) /\left[1+\left(\lambda_{c} \cdot \gamma\right)^{n}\right]
$$

where $\eta, \eta_{0}, \eta_{\infty}, \lambda_{c}, \gamma$, and $n$ are the surface viscosity (Pa.s), viscosity at zero shear rate (Pa.s), infinite viscosity $(\mathrm{Pa} \cdot \mathrm{s})$, a time constant, shear rate $\left(\mathrm{s}^{-1}\right)$, and a dimensionless exponent, respectively.

The dynamic rheological properties were described by data of storage modulus $\left(\mathrm{G}^{\prime}, \mathrm{Pa}\right)$, loss modulus $\left(\mathrm{G}^{\prime \prime}, \mathrm{Pa}\right)$, and compound viscosity $\left(\eta^{*}, \mathrm{~Pa} \cdot \mathrm{s}\right)$ from 0.1 to $100 \mathrm{rad} / \mathrm{s}$ under $0.3 \%$ of strain.

\subsubsection{Fourier-Transform Infrared Spectroscopy}

The Fourier-transform infrared (FT-IR) spectra of the RCE and ASKG/ACNF/RCE intelligent films were performed on a Thermo Fisher Scientific spectrometer (ATR model, Waltham, MA, USA) over a wavenumber range of $4000-600 \mathrm{~cm}^{-1}$ at a resolution of $4 \mathrm{~cm}^{-1}$.

\subsubsection{X-ray Diffractometry Spectroscopy}

The X-ray diffractometry (XRD) patterns of the ASKG, ACNF, and ASKG/ACNF/RCE intelligent films were obtained on a diffractometer (D/max-2200, Rigaku, Tokyo, Japan) with a scanning mode by using $\mathrm{Cu}-\mathrm{K} \alpha$ radiation from $5-40^{\circ}$ with $2^{\circ} / \mathrm{min}$ of scanning rate.

\subsubsection{Thermogravimetric Analysis}

The thermostability of the ASKG/ACNF/RCE intelligent films was compared through thermogravimetric analysis (TGA) and derivative thermogravimetric analysis (DTG) on a TGA Q500 TA instrument (Thermo Fisher Scientific, Waltham, MA, USA) from room temperature to $600{ }^{\circ} \mathrm{C}$ at $10^{\circ} \mathrm{C} / \mathrm{min}$ under $99.999 \%$ of nitrogen atmosphere. 


\subsubsection{Morphology Analysis}

The micro-morphology of the freeze-dried ACNF was tested on a transmission electron microscope (JEM-2100, JEOL Co., Ltd., Tokyo, Japan) at an accelerating voltage at $200 \mathrm{kV}$ and a $5000 \times$ magnification. After spraying a thin layer of gold, the fractured section and surface morphology of the samples were tested by using SIGMA 500 high-resolution field emission scanning electron microscope (Carl Zeiss, Jena, Germany), at $6 \mathrm{kV}$ of acceleration voltage.

\subsubsection{Mechanical Properties}

All films were stored at a $43 \%$ relative humidity for $48 \mathrm{~h}$ before testing to eliminate the influence of moisture on the test results. The thickness of the samples (strip of $15 \mathrm{~mm} \times 80 \mathrm{~mm}$ ) was tested by using ID-C112XBS micrometer (Mitutoyo Corp., Tokyo, Japan) and tensile strength (TS), and elongation at break (EB) of the samples (strip of $15 \mathrm{~mm} \times 80 \mathrm{~mm}$ ) was tested by using XLW-PC magnum experiment machine (Labthink, Jinan, China) at a strain rate of $300 \mathrm{~mm} / \mathrm{min}$.

\subsubsection{Barrier Properties}

The film oxygen permeability (OP) was tested by using OX2/230 oxygen permeability tester (Labthink, Jinan, China), according to the instructions.

The film water vapor permeability (WVP) was tested according to the literature [25]. A container that contained absolutely anhydrous calcium chloride $\left(\mathrm{CaCl}_{2}\right)$ was sealed with the samples and weighed every $30 \mathrm{~min}$ at $25^{\circ} \mathrm{C}$ and a $75 \%$ relative humidity. When the mass stopped changing, the WVP values were calculated according to related parameters.

\subsubsection{Light Transmittance Analysis}

The light transmittance of the samples was scanned on an UV-2600 ultraviolet (UV)-visible (Vis) spectrophotometer (Shimadzu, Tokyo, Japan) over all th wavelengths at $25^{\circ} \mathrm{C}$.

\subsubsection{Release Test}

$0.05 \mathrm{~g}$ of AFR15 film was added to $10 \mathrm{~mL}$ of different concentrations of ethanol solution $(75 \%$ and $100 \%, v / v)$ and oscillated for $12 \mathrm{~h}$ at $100 \mathrm{rpm}$ at room temperature. The residue solution spectra were scanned from 475-800 $\mathrm{nm}$ on UV-2600 UV-Vis spectrophotometer.

\subsubsection{Water-Sensitivity Test of Intelligent Films}

The water sensitivity of the intelligent films was evaluated from the water-contact angle, which was determined on an OCA20 video optical-contact-angle measurement instrument (Dataphysics, Filderstadt, Germany) by the pendant-drop method at $25^{\circ} \mathrm{C}$. Deionized water $(5 \mu \mathrm{L})$ was automatically pressed with an injector onto the intelligent film surface, and the contact angle data of each intelligent film were analyzed and collected by a CCD video system on the computer.

\subsubsection{Chroma-Response Test}

The $L^{*}, a^{*}, b^{*}$, and $\Delta E$ values of the samples (strips: $20 \mathrm{~mm} \times 40 \mathrm{~mm}$ ) at different pHs and concentrated $\mathrm{NH}_{3}$ condition were tested by using CM-2600d colorimeter (KONICA MINOLTA, Tokyo, Japan).

The chroma-response of the intelligent films to buffer solutions ( $\mathrm{pH}=3.0$ to 10.0) was tested after the samples were immersed in $10 \mathrm{~mL}$ of buffer solutions for a certain time. Subsequently, the sample's color was tested.

Before $\mathrm{NH}_{3}$-response test, the samples were stored first in containers with relative humidity of $33 \%, 75 \%$, and $90 \%$ for $12 \mathrm{~h}$ at $25^{\circ} \mathrm{C}$. Afterwards, $5 \mathrm{~mL}$ of ammonia was added into the containers. The chroma parameters of the samples were tested after $10 \mathrm{~min}$. 


\subsubsection{3. $\mathrm{pH}$ and Total Volatile Basic Nitrogen of Freshwater Shrimp}

The freshwater shrimp pH was tested according to GB 5009.237-2016 (a Chinese National Standard). Briefly, $10 \mathrm{~g}$ of sample was added to $100 \mathrm{~g}$ of $0.1 \mathrm{~mol} / \mathrm{L} \mathrm{KCl}$ solution and then homogenized for $30 \mathrm{~min}$. Subsequently, the mixture $\mathrm{pH}$ was tested by using PHSJ-3F pH meter (INESA, Shanghai, China).

The total volatile basic nitrogen (TVB-N) of freshwater shrimp was tested according to Chinese National Standard GB 5009.228-2016. Briefly, $20 \mathrm{~g}$ of milled sample was added to $100 \mathrm{~mL}$ of distilled water, which was cooled after boiling and oscillated for $30 \mathrm{~min}$. Next, the mixture was centrifuged at $3000 \mathrm{rpm}$ for $10 \mathrm{~min}$. Afterwards, $5 \mathrm{~mL}$ of supernatant was alkalized by $5 \mathrm{~mL}$ of MgO suspension $(10 \mathrm{~g} / \mathrm{L})$. Steam distillation was conducted on a semi-micro Kjeldahl analyzer (Beijing Bonokin Technology Co. Ltd., Beijing, China) for $5 \mathrm{~min}$ and then absorbed by $10 \mathrm{~mL}$ of $20 \mathrm{~g} / \mathrm{L}$ boric acid solution. Finally, the boric acid solution containing TVB-N was precisely titrated with $0.01 \mathrm{~mol} / \mathrm{L} \mathrm{HCl}$ solution. The TVB-N value was calculated and expressed in $\mathrm{mg} / 100 \mathrm{~g}$.

\subsubsection{Freshness Detection Test}

Before testing, the color parameter of the AFR-10P film $(15 \mathrm{~mm} \times 15 \mathrm{~mm}, \sim 0.01 \mathrm{~g})$ was tested. The sample was placed at a $43 \%$ humidity for $24 \mathrm{~h}$. Subsequently, $25 \mathrm{~g}$ of freshwater shrimp was used in the experiment at $20^{\circ} \mathrm{C}$. When the color of the film changed, the color parameter should be tested immediately. Figure 1 shows the specific test diagram.

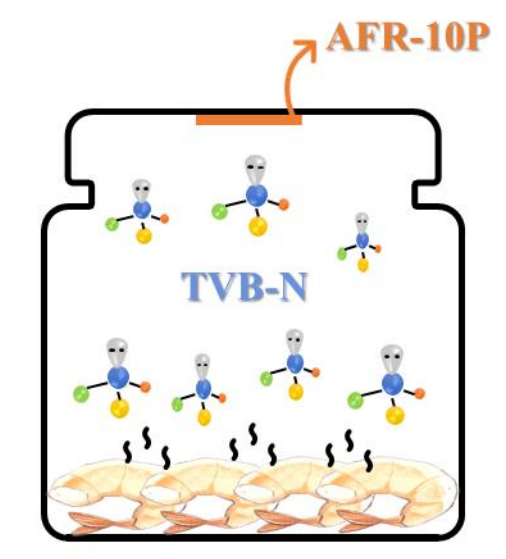

Figure 1. Detecting experiment schematic.

\subsubsection{Statistical Treatment}

SPSS 19.0 software was used to analyze all the data and Duncan multiple comparisons $(p<0.05)$ was used to analyze the discrepancies among them. The results are expressed in lowercase letters in figures and superscripts in tables.

\section{Results and Discussions}

\subsection{Zeta Potential Analysis}

The related data of RCE, ACNF, AFR0, AFR5, AFR10, and AFR15 solutions in Figure 2 indicate that the charge of the RCE solution is $-6.1 \mathrm{mV}$ [38] and the charge of ACNF solution is $-47.0 \mathrm{mV}$ [39]. The charge of the AFR0 solution is $-17.4 \mathrm{mV}$, which is related to the offset between the positive and negative charges [39]. When RCE increased from $0 \%$ to $15 \%$, it also increased from -17.4 to $-12.3 \mathrm{mV}$, which indicates that an electrostatic interaction between the flavylium cations in $\mathrm{RCE}$ and the $\mathrm{COO}^{-}$in ACNF occurred. 


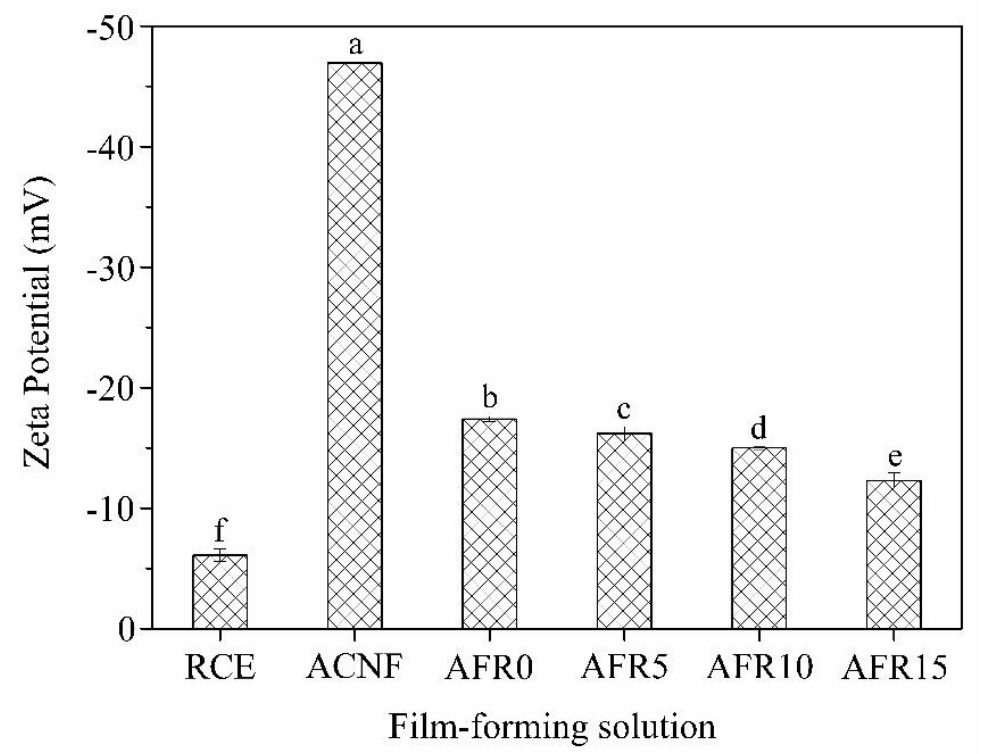

Figure 2. Zeta potential of film-forming solution with different red cabbage extracts (RCE) amounts.

\subsection{Rheological Analysis}

\subsubsection{Steady Rheological Analysis}

Figure 3 shows that the viscosity of all film-forming solutions decreased with the shear rate increased (characteristics of non-Newtonian fluids), which indicates that the hydrogen bonds that were formed by ASKG, ACNF, glycerol, and RCE were destroyed by the shearing force, and the original complicated network structure could not be restored within a certain time [40]. This result is attributed to the small molecular structure of RCE that could penetrate the complicated network structure easily formed among each content, and new hydrogen bonds formed between the ASKG, ACNF, glycerol and RCE. The complex that formed between the RCE and ACNF by the electrostatic attraction also broke the complicated network structure in film-forming solutions.

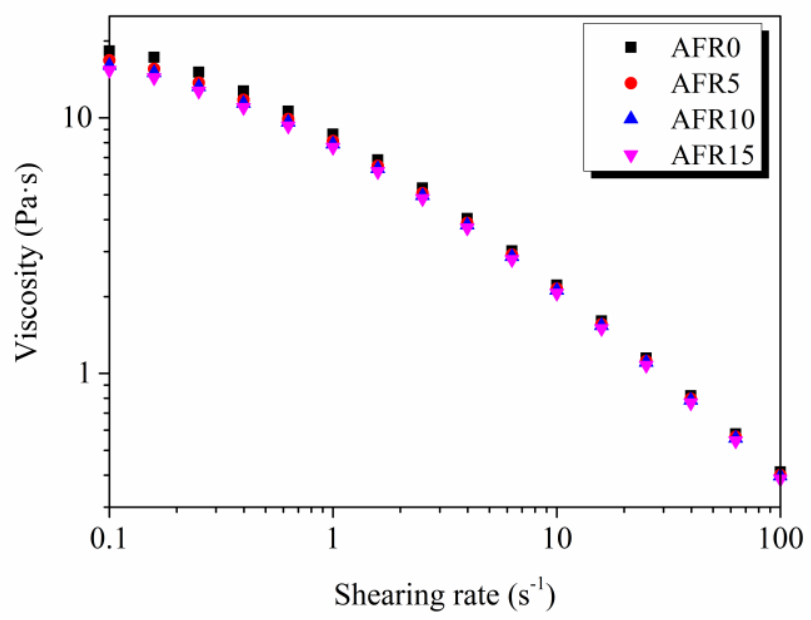

Figure 3. Effect of the RCE amount on steady rheological properties of film-forming solutions.

Table 1 shows that the Cross model is suitable for fitting the ASKG/ACNF/RCE film-forming solutions $\left(R^{2}>0.999\right)$, and the $\eta_{0}$ and $K$ values decreased from 1.3857 to $1.3015 \mathrm{~Pa} \cdot \mathrm{s}$ and from 2.1880 to $1.8871 \mathrm{~s}$ with an increase of RCE from $0 \%$ to $15 \%$, respectively. These results are related to the RCE addition, which broke the complicated network structure that formed between the ASKG, ACNF, and glycerol. Entanglements among the ACNF chains weakly decreased the weakly. Moreover, $p$ values $<1$ 
show that all of the solutions were pseudoplastic fluids [41]. These results reveal that RCE changed the network formed by ASKG, ACNF and glycerol molecules.

Table 1. The fitting data of Cross model.

\begin{tabular}{ccccc}
\hline Film-Forming Solution & $\eta_{\mathbf{0}}$ (Pa·s) & $\boldsymbol{K}(\mathbf{s})$ & $\boldsymbol{p}$ & $\boldsymbol{R}^{\mathbf{2}}$ \\
\hline AFR0 & $1.3857 \pm 0.8004$ & $2.1880 \pm 0.1963$ & $0.7639 \pm 0.0315$ & 0.9994 \\
AFR5 & $1.3538 \pm 0.3542$ & $2.1631 \pm 0.0974$ & $0.7236 \pm 0.0138$ & 0.9999 \\
AFR10 & $1.3250 \pm 0.4616$ & $1.9931 \pm 0.1225$ & $0.7348 \pm 0.0206$ & 0.9997 \\
AFR15 & $1.3015 \pm 0.3603$ & $1.8871 \pm 0.0955$ & $0.7350 \pm 0.0175$ & 0.9998 \\
\hline
\end{tabular}

\subsubsection{Dynamic Rheological Analysis}

As shown in Figure 4, all of the film-forming solutions were weak gel systems, because a crossover point between $G^{\prime \prime}$ and $G^{\prime}$ curves existed [42]. The $\eta^{*}$ value decreased as angular frequency increasing. The crossover point between $G^{\prime}$ and $G^{\prime \prime}$ shifted from 3.09 to $3.58 \mathrm{rad} / \mathrm{s}$ with an increase of RCE from $0 \%$ to $15 \%$, which was attributed to the electrostatic attraction between RCE and ACNF changed the complicated network structure. These results show that RCE exhibited plasticizing effects, to some extent. However, RCE addition did not change the network system properties of the film-forming solutions [43]. These results are agreed with the steady rheological analysis.
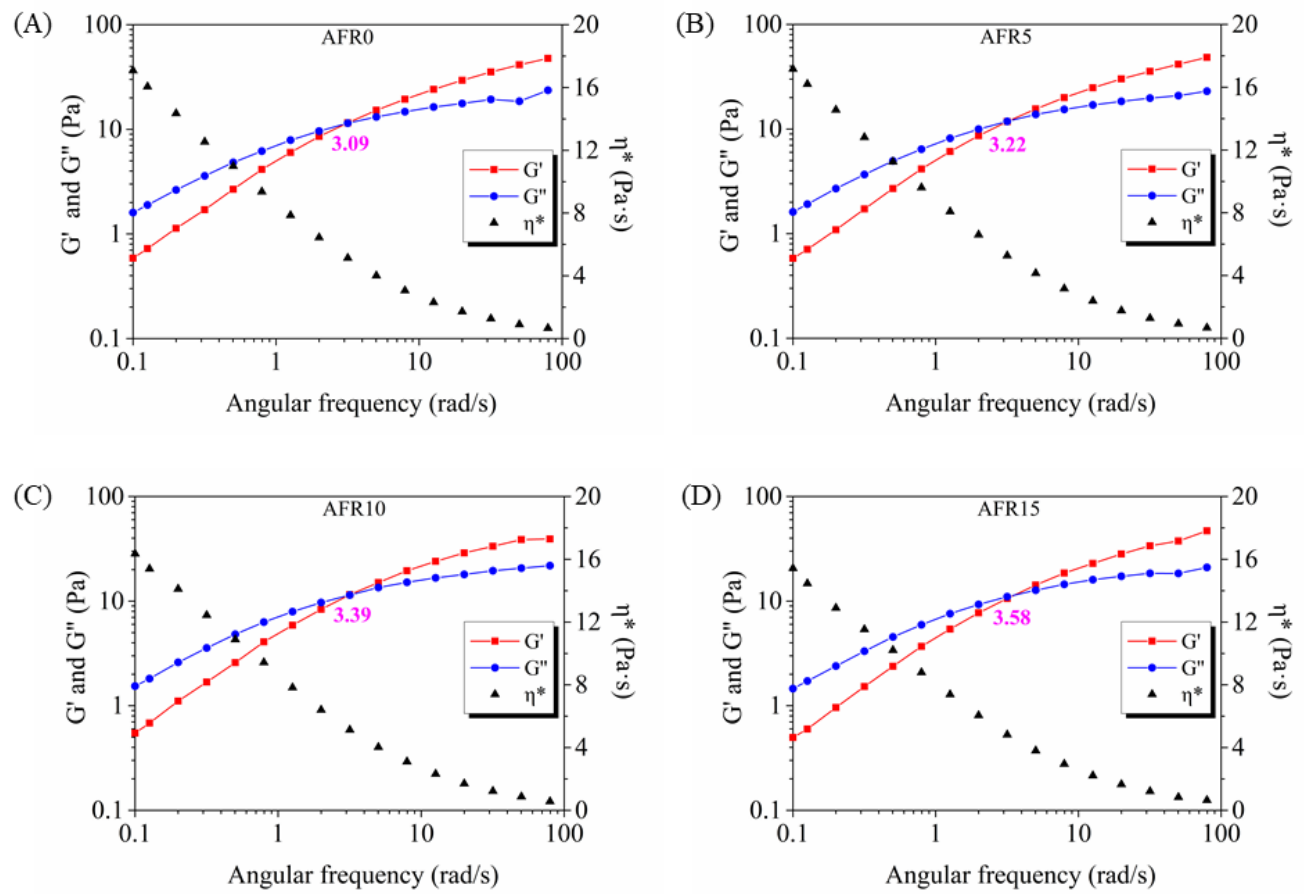

Figure 4. Effect of the RCE amount on dynamic rheological properties of film-forming solutions: AFR0 film-forming solution (A), AFR5 film-forming solution (B), AFR10 film-forming solution (C), and AFR15 film-forming solution (D).

\subsection{FT-IR Analysis}

The RCE spectrum shows that the bands at $3308,1638,1414$, and $1045 \mathrm{~cm}^{-1}$ were related to the $\mathrm{O}-\mathrm{H}$ stretching vibration in hydroxyl, the $\mathrm{C}=\mathrm{C}$ stretching vibration in aromatic ring, the $\mathrm{C}-\mathrm{O}$ bending vibration in phenols, and the $\mathrm{O}-\mathrm{C}$ stretching vibration in flavonoid, respectively [22]. Figure $5 \mathrm{~b}$ shows that the bands at 3289,2927 , and $2885 \mathrm{~cm}^{-1}$ of AFR0 film were related to the O-H stretching vibration in hydroxyl, the $\mathrm{C}-\mathrm{H}$ stretching vibration of the film components, respectively. Bands at 1644 and $1416 \mathrm{~cm}^{-1}$ were related to the $\mathrm{C}=\mathrm{O}$ stretching vibration and $-\mathrm{COO}-$ stretching vibration $[44,45]$. 
The bands at 1021,920 , and $868 \mathrm{~cm}^{-1}$ were related to the characteristic stretching vibration of $\mathrm{C}-\mathrm{O}$ and $\mathrm{O}-\mathrm{C}$ in pyran ring, respectively [46].

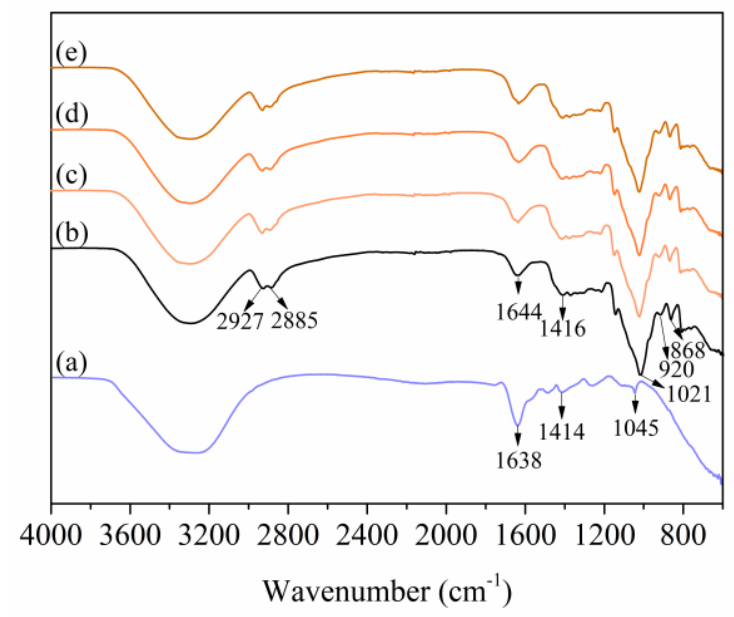

Figure 5. Fourier-transform infrared (FT-IR) spectra of RCE and intelligent films: RCE (a), AFR0 (b), AFR5 (c), AFR10 (d), and AFR15 (e).

After RCE addition, the band at $3289 \mathrm{~cm}^{-1}$ shifted to a low wavenumber and the band at $2924 \mathrm{~cm}^{-1}$ was enhanced, which indicates that the hydrogen bonds among the ASKG, ACNF and glycerol were broken and new hydrogen bonds formed [47]. Bands at 1644 and $1412 \mathrm{~cm}^{-1}$ broadened and shifted to a low wavenumber, which indicates that an electrostatic attraction occurred between RCE and ACNF [22]. All of those results show that RCE was locked into the intelligent film through electrostatic attraction with ACNF.

\subsection{XRD Analysis}

Figure 6a shows that a weak peak at $11.8^{\circ}$ and two broad peaks at $16.4^{\circ}$ and $22.2^{\circ}$ were the characteristic polysaccharide peaks of ASKG. Figure $6 \mathrm{~b}$ shows two peaks at $15.4^{\circ}$ and $22.5^{\circ}$ in the XRD pattern of ACNF, which indicates a cellulose I crystal structure [48].

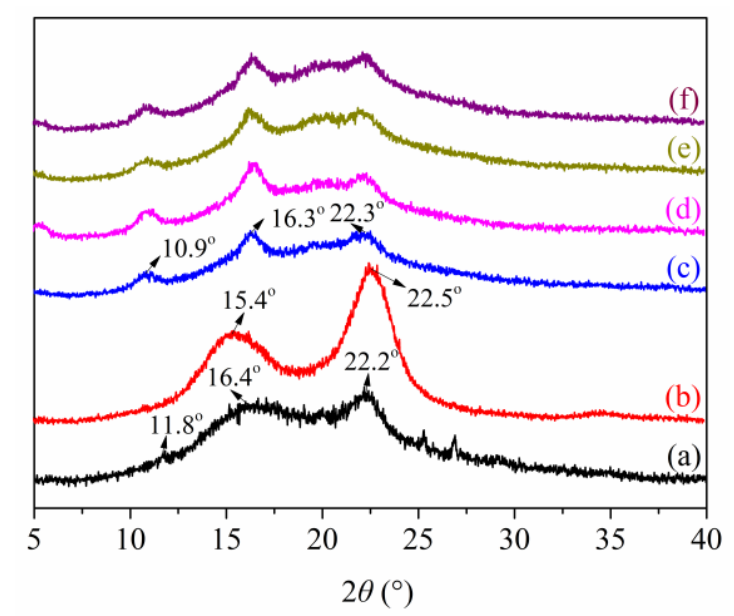

Figure 6. X-ray diffractometry (XRD) patterns of Artemisia sphaerocephala Krasch. gum (ASKG) (a), anionic cellulose nanofiber (ACNF) (b), AFR0 (c), AFR5 (d), AFR10 (e), and AFR15 (f) films.

The XRD pattern of the AFR0 film (Figure 6c) shows three characteristic peaks at $10.9^{\circ}, 16.3^{\circ}$, and $22.3^{\circ}$. The diffraction peaks indicate that ACNF rearranged ASKG molecular chains and the chains blended. After RCE addition, the peak around $16.3^{\circ}$ was enhanced, which indicates that RCE addition 
broke the complicated network structure that formed between ASKG and ACNF by electrostatic interaction. The peak at $16.3^{\circ}$ decreased with a further increase in RCE, which indicates that the electrostatic interaction between RCE and ACNF changed the crystal structure of the intelligent film.

\subsection{Thermogravimetric Analysis}

Figure 7 shows that three mass loss peaks can be observed in AFR0 film; the mass loss peaks at $69.07,186.04$, and $287.81^{\circ} \mathrm{C}$ were the loss of adsorbed water [49], the decomposition of glycerol [23], and the decomposition of ASKG and ACNF $[23,50]$. After RCE addition, the thermal decomposition temperature of the third mass loss peak shifted from $287.81^{\circ} \mathrm{C}$ to $281.38{ }^{\circ} \mathrm{C}$, which indicates that the RCE broke the tightly complicated network structure between the ASKG and ACNF chains.

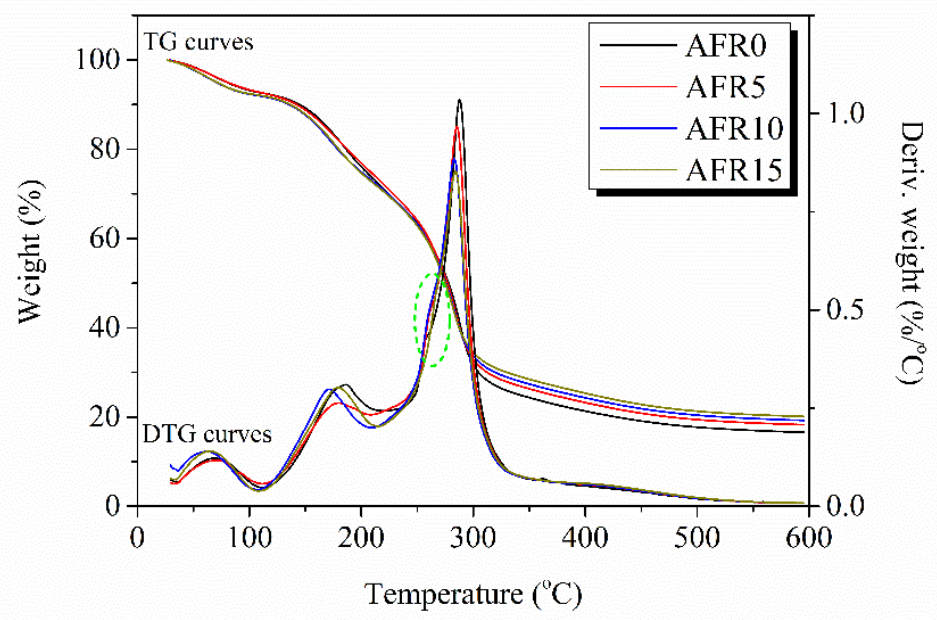

Figure 7. Thermogravimetric (TG) and derivative thermogravimetric (DTG) curves of ASKG/ACNF/RCE intelligent films.

\subsection{TEM and SEM Observation}

Figure 8 exhibits the ACNF morphology and the flat/cross-sectional surfaces of the intelligent films. Figure $8 \mathrm{~A}$ shows that the $1 \%$ of ACNF solution was a transparent milky white, which indicates that the ACNF was at the nanoscale. The ACNF showed a filament structure with a nanometer diameter and a micron length, according to the TEM image. The filaments were entangled.

(A)

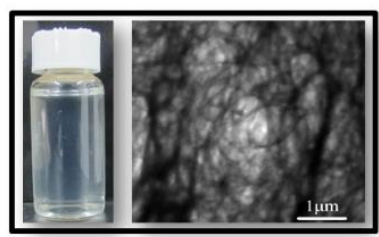

(B)
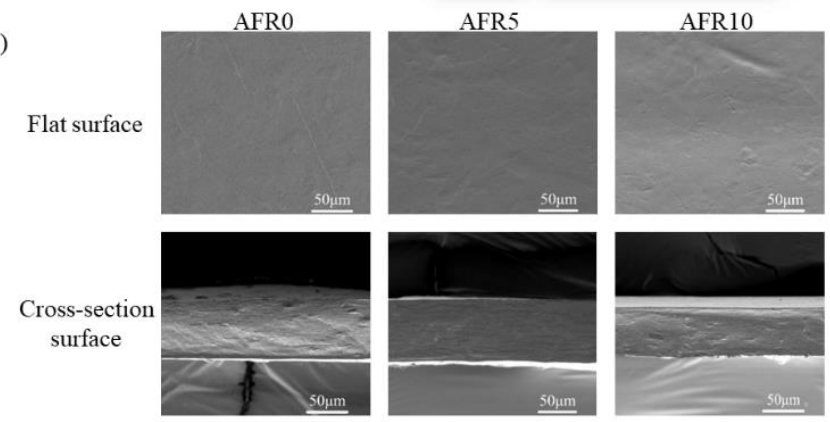
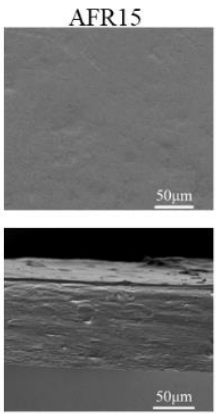

Figure 8. TEM picture (5000 magnification) of ACNF (A), SEM pictures (500 magnification) of the flat and cross-section surface morphology of intelligent films (B). 
As shown in Figure 8B, all of the flat surfaces of the intelligent films were homogeneous, but wrinkled, which is attributed to the long filament morphology of ACNF. Layered structures were visible in the cross-section surface of the AFR0 film, because the peeling effects between the ACNF and ASKG during brittle fracture in liquid nitrogen. After RCE addition, the layered structures in the cross-sectional surfaces of the intelligent films increased, which indicates that the electrostatic attraction between RCE and ACNF broke the arrangement of molecular chains and made the peeling effects of ACNF easier. A further increase in the amount of RCE added, the layered structures in the cross-section surfaces decreased, because new hydrogen bonds formed among the film-forming polymers and the rearrangement of molecular chains occurred. Based on all of the above analyses, the schematic structure of the ASKG/ACNF/RCE intelligent film is shown in Figure 9.
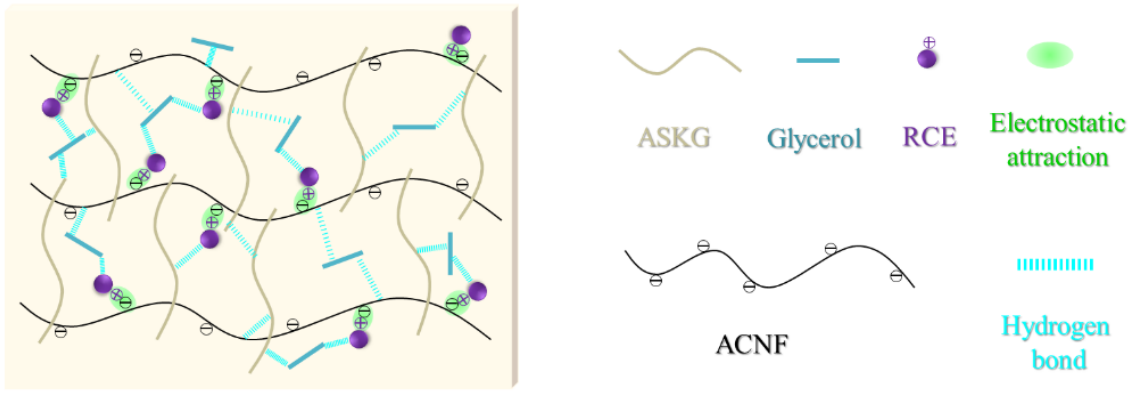

Figure 9. Effect of the RCE amount on mechanical properties of intelligent films.

\subsection{Mechanical Properties}

Figure 10 shows that the thickness of the intelligent films slightly increased from $0.061 \mathrm{~mm}$ to $0.066 \mathrm{~mm}$, owing to the increase of solid polymers, moreover, the tensile strength decreased from 43.23 to $24.83 \mathrm{MPa}$, but the elongation at break increased from $56.13 \%$ to $75.87 \%$ with the increase of RCE from $0 \%$ to $15 \%$.

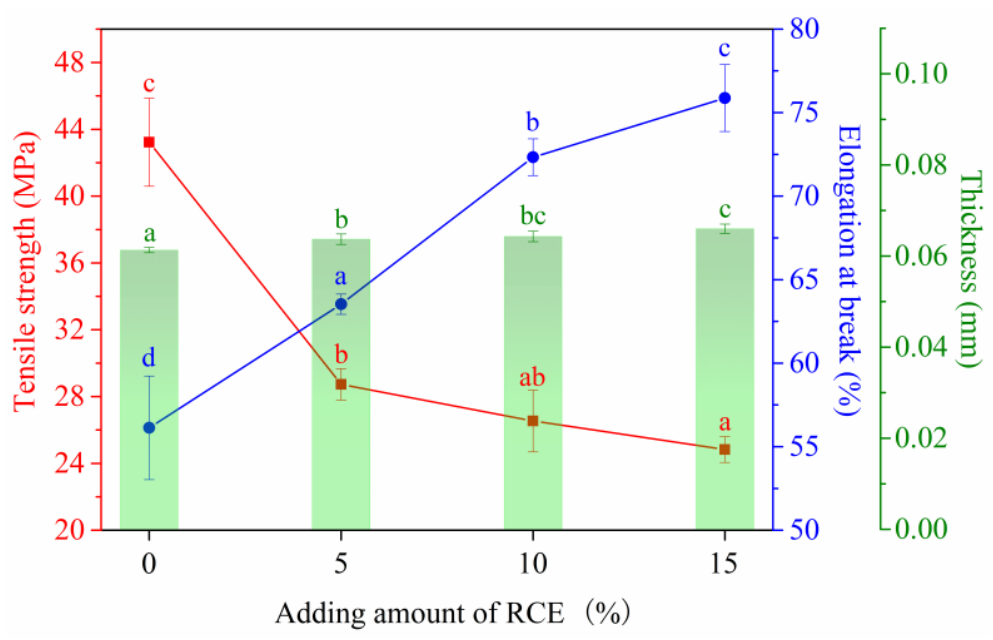

Figure 10. Effect of the RCE amount on mechanical properties of intelligent films.

\subsection{Oxygen and Water Vapor Permeabilities}

Figure 11 shows that the OP and WVP values of AFR5, AFR10, and AFR15 intelligent films were higher than the AFR0 intelligent film, owing to the electrostatic attraction between RCE and ACNF that broke the tight structure that formed by ASKG, ACNF, and glycerol. With an increase in RCE from $10 \%$ to $15 \%$, the two values slightly decreased from 0.0169 to $0.0115\left(\left(\mathrm{~cm}^{3} \cdot \mathrm{mm}\right) /\left(\mathrm{m}^{2} \cdot\right.\right.$ day $\left.\left.\cdot \mathrm{atm}\right)\right)$ and from 4.5859 to $3.8494 \times 10^{-10} \mathrm{~g} /(\mathrm{s} \cdot \mathrm{m} \cdot \mathrm{Pa})$, respectively. This result is attributed to the formation of 
a new tight network structure that formed by RCE, ASKG, ACNF and glycerol [51]. The developed intelligent films retained excellent oxygen and water vapor barrier properties.

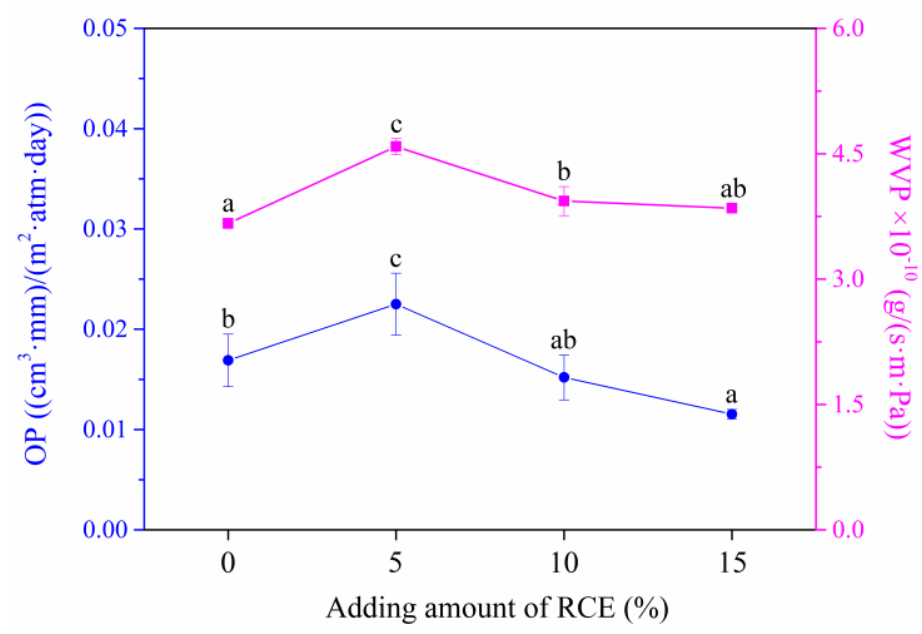

Figure 11. Effect of the RCE amount on oxygen barrier and water vapor barrier properties of intelligent films.

\subsection{Light Transmission of Intelligent Films}

Figure 12 shows that the light transmission of the intelligent films decreased from $49.96 \%$ to $36.75 \%$ with an increase in RCE from $0 \%$ to $15 \%$ (at $600 \mathrm{~nm}$ ), owing to the RCE, broke the ordered arrangement of ASKG and ACNF molecular chains, so that the light scattering and refraction increased. The entangled structure of the ACNF also increased the light scattering and reflection. The intelligent films showed UV light shielding effects when the amount of RCE added exceeded 5\%, which indicates that the AFR10 and AFR15 films could reduce food spoilage that is caused by UV light.

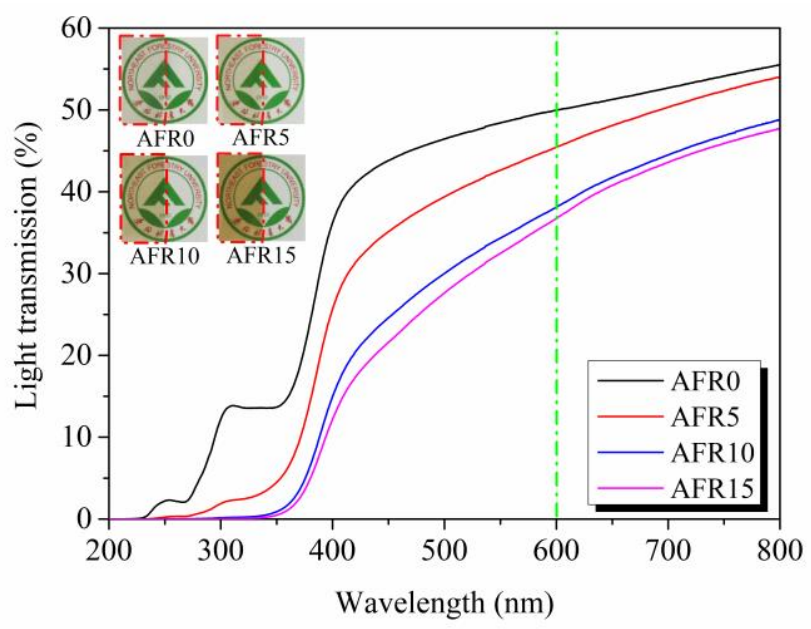

Figure 12. Effect of the RCE amount on light transparency properties of intelligent films.

\subsection{Water-Sensitivity Analysis}

Figure 13 shows the water-contact-angle data of the ASKG/ACNF/RCE and ASKG/CMC.Na/RCE intelligent films. It shows that the contact angle of the AFR0 film was $102^{\circ}$, which indicates a low water sensitivity, owing to the excessively tight network structure of the AFR0 film and the hydrophobic properties of the ACNF. An increase of RCE resulted in a decrease of contact angle. However, the contact angle remained at $93.25^{\circ}$ when the amount of RCE added reached $15 \%$, which indicates a low water sensitivity. These results were attributed to the RCE addition that broke the tight structure that formed 
among the ASKG, ACNF and glycerol, and promoted water penetration. When compared with the ASKG/CMC.Na/RCE intelligent films in our previous work [25], the contact angle of films that contained ACNF were higher than those that contained CMC $\cdot \mathrm{Na}$, which made them suitable for use under higher humidity conditions.

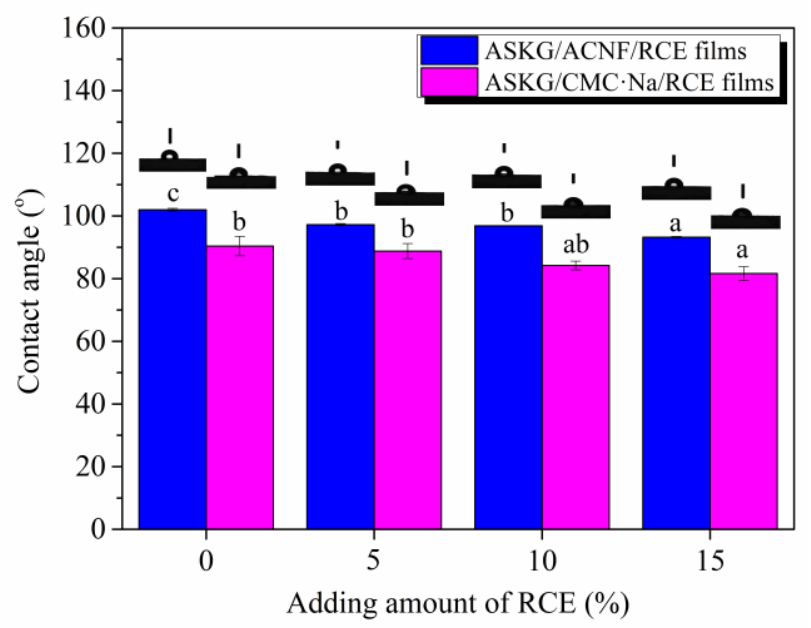

Figure 13. Effect of the RCE amount on water contact angle of ASKG/ACNF/RCE intelligent films and ASKG/CMC·Na/RCE intelligent films.

\subsection{Release Analysis}

The release test that was based on the AFR15 film was conducted for evaluating the locking effects between the ACNF and RCE. Figure 14 shows that a maximum absorbance of the RCE solution could be observed at $538 \mathrm{~nm}$, with a value of 0.089 . The maximum absorbance of the $75 \%$ and $100 \%$ ethanol filtrates were 0 and the two filtrates were colorless after intelligent film immersion and oscillation for $12 \mathrm{~h}$, which indicates that the RCE was locked in the ACF15 film. The same result was obtained for the AFR5 and AFR10 films.

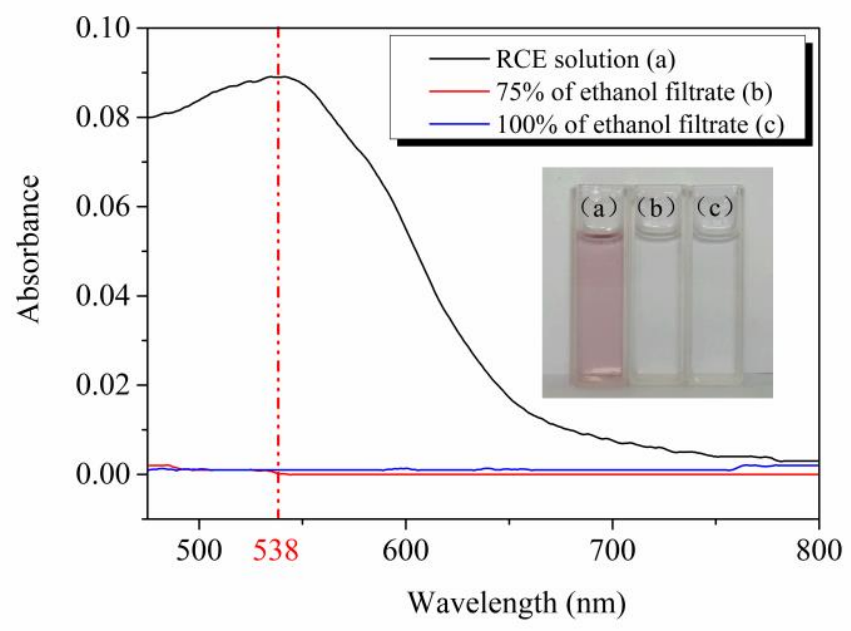

Figure 14. Visible light absorption curves of RCE solution and filtrates.

\subsection{Buffer Solutions and $\mathrm{NH}_{3}$ Atmosphere Response Analysis of Intelligent Films}

\subsubsection{Chroma-Response in Buffer Solution}

The intelligent film was dark-reddish-purple, grayish-purple, dark-brown, atropurpureus, and yellowish-green at a $\mathrm{pH}$ of 3.0, 4.0-6.0, 7.0, 8.0-9.0, and 10.0 in Table 2, respectively. With an increase in $\mathrm{pH}$ from 3.0 to 6.0 , the $a^{*}$ value decreased, but the $b^{*}$ value showed the opposite trend, owing to an 
increase in the pseudo-base carbinol structure of the RCE. When the $\mathrm{pH}$ increased to 7.0, the $a^{*}$ and $b^{*}$ values decreased further, owing to the change in RCE structure from pseudo-base carbinol to the anionic form. A further increase in $\mathrm{pH}$ to 10.0 resulted in a decrease of the $a^{*}$ value to negative and an increase in the $b^{*}$ value, because the change in RCE structure to chalcone [52]. The $\Delta E$ values of the AFR10 and AFR15 films exceeded 5, which indicates that the color differences could be observed by the eye [53].

Table 2. The colorimetric parameters and photographs of intelligent films under different buffer solutions.

\begin{tabular}{|c|c|c|c|c|c|c|c|}
\hline Sample & $\mathrm{pH}$ & $L^{*}$ & $a^{*}$ & $b^{*}$ & $\Delta E$ & Before & After \\
\hline \multirow{8}{*}{ AFR5 } & 3.0 & $79.91 \pm 0.36^{\mathrm{a}}$ & $6.13 \pm 0.40^{\mathrm{f}}$ & $-2.98 \pm 0.39^{a}$ & $6.18 \pm 0.31^{d}$ & & \\
\hline & 4.0 & $81.31 \pm 0.75^{b}$ & $2.86 \pm 0.08 \mathrm{e}^{\mathrm{e}}$ & $-3.47 \pm 0.86^{a}$ & $4.84 \pm 0.40^{\mathrm{cd}}$ & & \\
\hline & 5.0 & $82.01 \pm 0.47^{b c}$ & $2.24 \pm 0.03^{\mathrm{d}}$ & $-3.80 \pm 0.73^{\mathrm{a}}$ & $4.92 \pm 1.38^{\mathrm{cd}}$ & & \\
\hline & 6.0 & $81.81 \pm 0.43^{b}$ & $2.02 \pm 0.02^{\mathrm{d}}$ & $-3.31 \pm 0.73^{a}$ & $4.23 \pm 0.23 \mathrm{bc}$ & & \\
\hline & 7.0 & $81.00 \pm 0.86^{\mathrm{ab}}$ & $1.24 \pm 0.03^{c}$ & $-1.19 \pm 1.37^{b}$ & $2.82 \pm 1.70^{a b}$ & & \\
\hline & 8.0 & $83.12 \pm 0.36^{c}$ & $1.33 \pm 0.05^{c}$ & $-4.43 \pm 0.35^{a}$ & $4.61 \pm 0.55^{\mathrm{cd}}$ & & \\
\hline & 9.0 & $82.05 \pm 0.58^{b c}$ & $-0.48 \pm 0.30^{b}$ & $-0.87 \pm 1.12^{c}$ & $2.37 \pm 0.53^{\mathrm{a}}$ & & \\
\hline & 10.0 & $79.90 \pm 0.97^{\mathrm{a}}$ & $-4.08 \pm 0.39^{a}$ & $-0.72 \pm 1.09^{c}$ & $6.12 \pm 0.37^{d}$ & & \\
\hline \multirow{8}{*}{ AFR10 } & 3.0 & $78.71 \pm 0.20^{b}$ & $5.86 \pm 0.33^{f}$ & $0.48 \pm 0.49^{b}$ & $10.46 \pm 1.02^{b c}$ & & \\
\hline & 4.0 & $78.08 \pm 1.01^{b}$ & $3.15 \pm 0.04 \mathrm{e}^{\mathrm{e}}$ & $2.62 \pm 1.04^{\mathrm{bc}}$ & $8.59 \pm 0.62 \mathrm{abc}$ & & \\
\hline & 5.0 & $77.92 \pm 0.22^{b}$ & $2.69 \pm 0.18 \mathrm{de}$ & $3.55 \pm 0.58^{\mathrm{cd}}$ & $8.871 \pm 0.77 \mathrm{abc}$ & & \\
\hline & 6.0 & $77.20 \pm 0.37^{b}$ & $2.44 \pm 0.07^{\text {cde }}$ & $3.94 \pm 0.24^{\mathrm{cd}}$ & $8.54 \pm 0.51^{a b c}$ & & \\
\hline & 7.0 & $77.89 \pm 1.52^{b}$ & $1.93 \pm 0.20^{b c}$ & $4.25 \pm 2.86^{\mathrm{cd}}$ & $7.64 \pm 3.35^{\mathrm{a}}$ & & \\
\hline & 8.0 & $81.31 \pm 0.77^{\mathrm{c}}$ & $1.98 \pm 0.06^{\mathrm{bcd}}$ & $-2.39 \pm 1.14^{\mathrm{a}}$ & $11.22 \pm 1.55^{\mathrm{c}}$ & & \\
\hline & 9.0 & $77.48 \pm 0.60^{b}$ & $1.66 \pm 0.22^{b}$ & $4.50 \pm 0.37^{c d}$ & $7.10 \pm 0.21^{\mathrm{a}}$ & & \\
\hline & 10.0 & $73.76 \pm 0.76^{\mathrm{a}}$ & $-2.83 \pm 1.01^{\mathrm{a}}$ & $5.36 \pm 1.94^{\mathrm{d}}$ & $8.16 \pm 0.68^{a b}$ & & \\
\hline \multirow{8}{*}{ AFR15 } & 3.0 & $77.82 \pm 0.77^{c}$ & $6.36 \pm 0.46^{\mathrm{e}}$ & $3.24 \pm 0.97^{\mathrm{b}}$ & $12.48 \pm 0.83^{\mathrm{ab}}$ & & \\
\hline & 4.0 & $78.27 \pm 2.53^{\mathrm{cd}}$ & $3.93 \pm 0.78^{d}$ & $4.08 \pm 4.68^{b}$ & $12.14 \pm 4.49 \mathrm{ab}$ & & \\
\hline & 5.0 & $77.51 \pm 0.76^{b c}$ & $3.08 \pm 0.27^{\mathrm{cd}}$ & $6.33 \pm 1.04^{b c}$ & $10.37 \pm 1.28^{a b}$ & & \\
\hline & 6.0 & $79.20 \pm 0.31^{\mathrm{cd}}$ & $2.57 \pm 0.08^{b c}$ & $2.83 \pm 0.54^{\mathrm{b}}$ & $14.05 \pm 1.03^{\mathrm{bc}}$ & & \\
\hline & 7.0 & $75.48 \pm 0.85^{b}$ & $2.51 \pm 0.14^{b c}$ & $8.94 \pm 1.10^{c}$ & $10.14 \pm 1.08^{\mathrm{a}}$ & & \\
\hline & 8.0 & $80.38 \pm 0.10^{d}$ & $2.25 \pm 0.01 \mathrm{bc}$ & $-0.92 \pm 0.61^{\mathrm{a}}$ & $16.53 \pm 0.29^{c}$ & & \\
\hline & 9.0 & $78.05 \pm 1.04^{\mathrm{c}}$ & $1.80 \pm 0.19^{b}$ & $3.70 \pm 1.78^{b}$ & $12.02 \pm 2.33^{\mathrm{ab}}$ & & \\
\hline & 10.0 & $72.55 \pm 1.28^{a}$ & $-1.95 \pm 1.09^{\mathrm{a}}$ & $5.83 \pm 2.33 b c$ & $11.45 \pm 1.34^{\mathrm{ab}}$ & & \\
\hline
\end{tabular}

\subsubsection{Chroma-Response in $\mathrm{NH}_{3}$ Condition}

$\mathrm{NH}_{3}$ was selected to simulate the TVB-N that is produced by seafood to evaluate the practical application of the ASKG/ACNF/RCE intelligent films. As shown in Table 3, the $L^{*}$ values decreased as the RCE addition and relative humidity increased, which indicates that the developed film became dark. After increasing the relative humidity to $75 \%$, the $a^{*}$ and the $b^{*}$ values decreased, owing to the acceleration of the contact between $\mathrm{RCE}$ and $\mathrm{OH}^{-}$ions by the hydrophobic ACNF, which accelerated the structural change in RCE. 
Table 3. The colorimetric parameters and photographs of intelligent films under different humidities.

\begin{tabular}{|c|c|c|c|c|c|c|c|}
\hline Sample & Humidity & $L^{*}$ & $a^{*}$ & $b^{*}$ & $\Delta E$ & Before & After \\
\hline \multirow{3}{*}{ AFR5 } & $33 \%$ & $77.73 \pm 0.39^{a}$ & $-8.47 \pm 0.35^{\mathrm{a}}$ & $17.57 \pm 1.08^{c}$ & $20.29 \pm 1.47^{c}$ & & \\
\hline & $75 \%$ & $78.92 \pm 0.08^{b}$ & $-6.09 \pm 0.12^{b}$ & $11.87 \pm 0.22^{b}$ & $14.82 \pm 0.19^{b}$ & & \\
\hline & $90 \%$ & $79.34 \pm 0.25^{b}$ & $-0.11 \pm 0.07^{c}$ & $2.67 \pm 0.32^{\mathrm{a}}$ & $4.66 \pm 0.18^{a}$ & & \\
\hline \multirow{3}{*}{ AFR10 } & $33 \%$ & $70.66 \pm 0.44^{a}$ & $-7.22 \pm 0.03^{\mathrm{a}}$ & $31.95 \pm 0.81^{\mathrm{c}}$ & $25.02 \pm 1.10^{c}$ & & \\
\hline & $75 \%$ & $72.21 \pm 0.38^{b}$ & $-5.51 \pm 0.11^{b}$ & $25.41 \pm 1.19^{b}$ & $19.22 \pm 1.69^{b}$ & & \\
\hline & $90 \%$ & $73.97 \pm 0.55^{c}$ & $-2.25 \pm 0.38^{c}$ & $15.32 \pm 1.24^{\mathrm{a}}$ & $10.89 \pm 1.10^{\mathrm{a}}$ & & \\
\hline \multirow{3}{*}{ AFR15 } & $33 \%$ & $69.45 \pm 0.31^{\mathrm{a}}$ & $-4.92 \pm 0.22 \mathrm{a}$ & $31.48 \pm 0.73^{c}$ & $20.96 \pm 1.00^{c}$ & & \\
\hline & $75 \%$ & $69.48 \pm 0.32^{a}$ & $-3.51 \pm 0.28^{b}$ & $28.20 \pm 0.64^{b}$ & $17.09 \pm 0.75^{b}$ & & \\
\hline & $90 \%$ & $68.73 \pm 0.47^{a}$ & $-0.70 \pm 0.11^{c}$ & $24.21 \pm 0.93^{\mathrm{a}}$ & $12.29 \pm 0.51^{a}$ & & \\
\hline
\end{tabular}

${ }^{\mathrm{a}-\mathrm{c}}$ are the significant differences in the same parameters $(p<0.05)$.

When compared with ASKG/CMC.Na/RCE intelligent films in our previous work [25], the color change was slightly different, owing to the scattering and reflection of light that was caused by the long fiber morphology of the ACNF.

\subsection{Detecting Analysis of Intelligent Film for Freshwater Shrimp Freshness in Real Time}

Figure 15 shows changes in $\mathrm{pH}$ and TVB-N of the freshness shrimp, colorimetric parameters, and a photograph of the intelligent film and they are listed in Table 4. The $\mathrm{pH}$ and TVB-N of the fresh freshwater shrimp were 6.831 and $1.4047 \mathrm{mg} / 100 \mathrm{~g}$, respectively. The intelligent film was dark purple. After $12 \mathrm{~h}$, the two values increased to 7.163 and $20.0759 \mathrm{mg} / 100 \mathrm{~g}$, respectively. Table 4 shows that the $a^{*}$ value decreased to negative, but the $b^{*}$ value showed opposite changes. The intelligent film was yellow-green. The $\mathrm{pH}$ of the freshwater shrimp changed to alkaline and spoilage occurred after $12 \mathrm{~h}$ according to GB 2733-2015 (a Chinese National Standard). A further increase in storage time showed a more obvious increase in the two values. These results are attributed to protein and amino acid decomposition in freshwater shrimp into volatile nitrogen under the action of microorganisms [54]. According to our study, $\sim 0.01 \mathrm{~g}$ of intelligent film was suitable for detecting freshness information for $25 \mathrm{~g}$ of freshwater shrimp to consumers through a color change in real time.

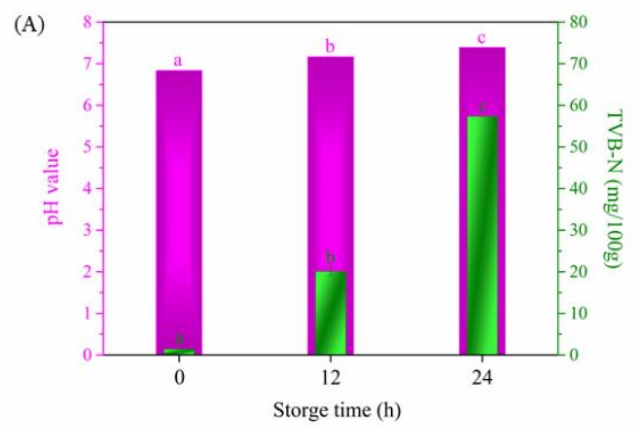

(B)

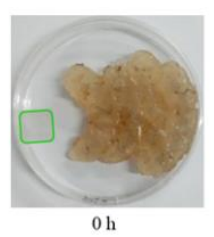

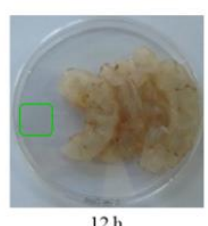

$12 \mathrm{~h}$

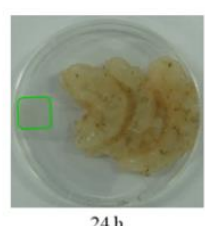

$24 \mathrm{~h}$

Figure 15. The $\mathrm{pH}$ and total volatile basic nitrogen (TVB-N) values of freshness shrimp, colorimetric parameters (A) and photograph (B) of intelligent at different storage times. 
Table 4. The colorimetric parameters and photographs of intelligent film.

\begin{tabular}{cccccc}
\hline Storage Time (h) & $\mathbf{L}^{*}$ & $\boldsymbol{a}^{*}$ & $\boldsymbol{b}^{*}$ & $\Delta \boldsymbol{E}$ & Photograph \\
\hline 0 & $75.09 \pm 0.58^{\mathrm{ab}}$ & $0.32 \pm 0.03^{\mathrm{c}}$ & $-0.31 \pm 0.52^{\mathrm{a}}$ & - & \\
12 & $75.78 \pm 0.99^{\mathrm{b}}$ & $-4.18 \pm 0.19^{\mathrm{b}}$ & $7.61 \pm 0.12^{\mathrm{b}}$ & $9.22 \pm 0.05^{\mathrm{b}}$ & \\
24 & $73.75 \pm 0.65^{\mathrm{a}}$ & $-5.05 \pm 0.21^{\mathrm{a}}$ & $10.35 \pm 0.41^{\mathrm{c}}$ & $12.04 \pm 0.83^{\mathrm{c}}$ & \\
\hline \multicolumn{5}{c}{${ }^{\mathrm{a}-\mathrm{c}}$ are the significant differences in the same parameters $(p<0.05)}$.
\end{tabular}

\section{Conclusions}

An intelligent and low water-sensitive ASKG-based film was developed and ACNF was selected as a reinforcing and locking compound to reduce films' water sensitivity and lock RCE. All of the film-forming solutions showed the characteristics of non-Newtonian fluids. The zeta potential and rheological results of the film-forming solutions indicated that RCE interacted with ACNF through electrostatic attraction and changed the complicated network structure in the film-forming solutions. The FTIR results were consistent with the above results. The XRD results showed that RCE addition changed film's crystalline state. The TG results revealed that RCE did not obviously change the stability of the intelligent films. TEM observation showed that ACNF was a filament structure with a nanometer diameter and a micron length. SEM observation showed that film's flat surfaces were homogeneous, but wrinkled, and the film's cross-section showed a layered structure. RCE addition reduced the TS and transmittance of the intelligent films from 43.23 to $24.83 \mathrm{MPa}$ and $49.96 \%$ to $36.75 \%$ at $600 \mathrm{~nm}$, but it increased the EB from $56.13 \%$ to $75.87 \%$. The OP and WVP of films that contained RCE was higher that the film without RCE, but the OP and WVP decreased from 0.0169 to $0.0115\left(\left(\mathrm{~cm}^{3} \cdot \mathrm{mm}\right) /\left(\mathrm{m}^{2} \cdot\right.\right.$ day $\left.\left.\cdot \mathrm{atm}\right)\right)$ and from $4.5859 \times 10^{-10}$ to $3.8494 \times 10^{-10} \mathrm{~g} /(\mathrm{s} \cdot \mathrm{m} \cdot \mathrm{Pa})$ with an increase in RCE addition from $10 \%$ to $15 \%$. The release results indicated that RCE has been locked in the intelligent films. The intelligent films could respond to buffer solutions and $\mathrm{NH}_{3}$ atmosphere through color changes. The contact angles of the intelligent films that contained ACNF were higher than those with CMC.Na. Moreover, $0.01 \mathrm{~g}$ of the AFR-10P film could detect the freshness information for $25 \mathrm{~g}$ of freshwater shrimp in real time and its color changed from dark-purple to yellow-green when the samples started to spoil. The developed films show potentials in edible and intelligent food packaging field.

Author Contributions: L.W. and T.L. conceived and designed the experiments; T.L. performed the experiments; L.W. and T.L. analyzed the data; T.L. wrote the paper; L.W. proofed the technical content. All authors have read and agreed to the published version of the manuscript.

Funding: This research was funded by the National Natural Science Foundation of China, grant number 31770618.

Conflicts of Interest: The authors declare no conflict of interest.

\section{References}

1. Oliveira, A.F.; Silveira, C.B.; Ernani, P.R.; Balbinot, E.S.; Soldi, V. Potassium ions release from polysaccharide films. J. Braz. Chem. Soc. 2011, 22, 211-216. [CrossRef]

2. Fang, Z.; Zhao, Y.; Warner, R.D.; Johnson, S.K. Active and intelligent packaging in meat industry. Trends Food Sci. Technol. 2017, 61, 60-71. [CrossRef]

3. Zeng, P.; Chen, X.; Qin, Y.R.; Zhang, Y.H.; Wang, X.P.; Wang, J.Y.; Ning, Z.X.; Ruan, Q.J.; Zhang, Y.S. Preparation and characterization of a novel colorimetric indicator film based on gelatin/polyvinyl alcohol incorporating mulberry anthocyanin extracts for monitoring fish freshness. Food Res. Int. 2019, 126, 108604. [CrossRef] [PubMed]

4. Wu, C.; Sun, J.; Chen, M.; Ge, Y.; Ma, J.; Hu, Y.; Pang, J.; Yan, Z. Effect of oxidized chitin nanocrystals and curcumin into chitosan films for seafood freshness monitoring. Food Hydrocoll. 2019, 95, 308-317. [CrossRef]

5. Zhai, X.; Li, Z.; Shi, J.; Huang, X.; Sun, Z.; Zhang, D.; Zou, X.; Sun, Y.; Zhang, J.; Holmes, M.; et al. A colorimetric hydrogen sulfide sensor based on gellan gum-silver nanoparticles bionanocomposite for monitoring of meat spoilage in intelligent packaging. Food Chem. 2019, 290, 135-143. [CrossRef] 
6. Choi, I.; Lee, J.Y.; Lacroix, M.; Han, J. Intelligent $\mathrm{pH}$ indicator film composed of agar/potato starch and anthocyanin extracts from purple sweet potato. Food Chem. 2017, 218, 122-128. [CrossRef]

7. Gutiérrez-Tauste, D.; Domènech, X.; Casañ-Pastor, N.; Ayllón, J.A. Characterization of methylene blue/TiO 2 hybrid thin films prepared by the liquid phase deposition (LPD) method: Application for fabrication of light-activated colorimetric oxygen indicators. J. Photochem. Photobiol. A 2007, 187, 45-52. [CrossRef]

8. Makote, R.; Collinson, M.M. Organically modified silicate films for stable pH sensors. Anal. Chim. Acta 1999, 394, 195-200. [CrossRef]

9. Dong, S.; Luo, M.; Peng, G.; Cheng, W. Broad range pH sensor based on sol-gel entrapped indicators on fibre optic. Sens. Actuators B 2008, 129, 94-98. [CrossRef]

10. Zhang, X.; Lu, S.; Chen, X. A visual $\mathrm{pH}$ sensing film using natural dyes from Bauhinia blakeana Dunn. Sens. Actuators B 2014, 198, 268-273. [CrossRef]

11. Roy, S.; Rhim, J.W. Preparation of carbohydrate-based functional composite films incorporated with curcumin. Food Hydrocoll. 2020, 98, 105302. [CrossRef]

12. Said, N.S.; Sarbon, N.M. Response surface methodology (RSM) of chicken skin gelatin based composite films with rice starch and curcumin incorporation. Polym. Test. 2019, 106161. [CrossRef]

13. Da Nascimento Silva, M.; de Matos Fonseca, J.; Feldhaus, H.K.; Soares, L.S.; Valencia, G.A.; de Maduro Campos, C.E.; Di Luccio, M.; Monteiro, A.R. Physical and morphological properties of hydroxypropyl methylcellulose films with curcumin polymorphs. Food Hydrocoll. 2019, 97, 105217. [CrossRef]

14. Koosha, M.; Hamedi, S. Intelligent Chitosan/PVA nanocomposite films containing black carrot anthocyanin and bentonite nanoclays with improved mechanical, thermal and antibacterial properties. Prog. Org. Coat. 2019, 127, 338-347. [CrossRef]

15. Carvalho, V.V.L.; Goncalves, J.O.; Silva, A.; Cadaval, T.R., Jr.; Pinto, L.A.A.; Lopes, T.J. Separation of anthocyanins extracted from red cabbage by adsorption onto chitosan films. Int. J. Biol. Macromol. 2019, 131, 905-911. [CrossRef] [PubMed]

16. Wu, C.; Li, Y.; Sun, J.; Lu, Y.; Tong, C.; Wang, L.; Yan, Z.; Pang, J. Novel konjac glucomannan films with oxidized chitin nanocrystals immobilized red cabbage anthocyanins for intelligent food packaging. Food Hydrocoll. 2020, 98, 105245. [CrossRef]

17. Yong, H.; Wang, X.; Bai, R.; Miao, Z.; Zhang, X.; Liu, J. Development of antioxidant and intelligent pH-sensing packaging films by incorporating purple-fleshed sweet potato extract into chitosan matrix. Food Hydrocoll. 2019, 90, 216-224. [CrossRef]

18. Zhang, J.; Zou, X.; Zhai, X.; Huang, X.; Jiang, C.; Holmes, M. Preparation of an intelligent pH film based on biodegradable polymers and roselle anthocyanins for monitoring pork freshness. Food Chem. 2019, 272, 306-312. [CrossRef]

19. Won, K.; Jang, N.Y.; Jeon, J. A Natural Component-Based Oxygen Indicator with In-Pack Activation for Intelligent Food Packaging. J. Agric. Food Chem. 2016, 64, 9675-9679. [CrossRef]

20. Krga, I.; Milenkovic, D. Anthocyanins: From Sources and Bioavailability to Cardiovascular-Health Benefits and Molecular Mechanisms of Action. J. Agric. Food Chem. 2019, 67, 1771-1783. [CrossRef]

21. Silva-Pereira, M.C.; Teixeira, J.A.; Pereira-Júnior, V.A.; Stefani, R. Chitosan/corn starch blend films with extract from Brassica oleraceae (red cabbage) as a visual indicator of fish deterioration. LWT Food Sci. Technol. 2015, 61, 258-262. [CrossRef]

22. Pourjavaher, S.; Almasi, H.; Meshkini, S.; Pirsa, S.; Parandi, E. Development of a colorimetric $\mathrm{pH}$ indicator based on bacterial cellulose nanofibers and red cabbage (Brassica oleraceae) extract. Carbohydr. Polym. 2017, 156, 193-201. [CrossRef] [PubMed]

23. Liang, T.; Wang, L. Preparation and characterization of a novel edible film based on Artemisia sphaerocephala Krasch. gum: Effects of type and concentration of plasticizers. Food Hydrocoll. 2018, 77, 502-508. [CrossRef]

24. Liang, T.; Sun, G.; Cao, L.; Li, J.; Wang, L. Rheological behavior of film-forming solutions and film properties from Artemisia sphaerocephala Krasch. gum and purple onion peel extract. Food Hydrocoll. 2018, 82, 124-134. [CrossRef]

25. Liang, T.; Sun, G.; Cao, L.; Li, J.; Wang, L. A pH and $\mathrm{NH}_{3}$ sensing intelligent film based on Artemisia sphaerocephala Krasch. gum and red cabbage anthocyanins anchored by carboxymethyl cellulose sodium added as a host complex. Food Hydrocoll. 2019, 87, 858-868. [CrossRef] 
26. Jayakumar, A.; Heera, K.V.; Sumi, T.S.; Joseph, M.; Mathew, S.; Praveen, G.; Nair, I.C.; Radhakrishnan, E.K. Starch-PVA composite films with zinc-oxide nanoparticles and phytochemicals as intelligent $\mathrm{pH}$ sensing wraps for food packaging application. Int. J. Biol. Macromol. 2019, 136, 395-403. [CrossRef]

27. Ebrahimi Tirtashi, F.; Moradi, M.; Tajik, H.; Forough, M.; Ezati, P.; Kuswandi, B. Cellulose/chitosan $\mathrm{pH}$-responsive indicator incorporated with carrot anthocyanins for intelligent food packaging. Int. J. Biol. Macromol. 2019, 136, 920-926. [CrossRef]

28. Andretta, R.; Luchese, C.L.; Tessaro, I.C.; Spada, J.C. Development and characterization of pH-indicator films based on cassava starch and blueberry residue by thermocompression. Food Hydrocoll. 2019, 93, 317-324. [CrossRef]

29. Huq, T.; Salmieri, S.; Khan, A.; Khan, R.A.; Le Tien, C.; Riedl, B.; Fraschini, C.; Bouchard, J.; Uribe-Calderon, J.; Kamal, M.R.; et al. Nanocrystalline cellulose (NCC) reinforced alginate based biodegradable nanocomposite film. Carbohydr. Polym. 2012, 90, 1757-1763. [CrossRef]

30. Atef, M.; Rezaei, M.; Behrooz, R. Preparation and characterization agar-based nanocomposite film reinforced by nanocrystalline cellulose. Int. J. Biol. Macromol. 2014, 70, 537-544. [CrossRef]

31. Chen, Q.; Shi, Y.; Chen, G.; Cai, M. Enhanced mechanical and hydrophobic properties of composite cassava starch films with stearic acid modified MCC (microcrystalline cellulose)/NCC (nanocellulose) as strength agent. Int. J. Biol. Macromol. 2020, 142, 846-854, in press. [CrossRef] [PubMed]

32. Zhao, K.; Wang, W.; Teng, A.; Zhang, K.; Ma, Y.; Duan, S.; Li, S.; Guo, Y. Using cellulose nanofibers to reinforce polysaccharide films: Blending vs layer-by-layer casting. Carbohydr. Polym. 2020, 227, 115264. [CrossRef] [PubMed]

33. Chinga-Carrasco, G. Cellulose fibres, nanofibrils and microfibrils: The morphological sequence of MFC components from a plant physiology and fibre technology point of view. Nanoscale Res. Lett. 2011, 6, 417. [CrossRef] [PubMed]

34. Akindoyo, J.O.; Ismail, N.H.; Mariatti, M. Performance of poly (vinyl alcohol) nanocomposite reinforced with hybrid TEMPO mediated cellulose-graphene filler. Polym. Test. 2019, 80, 106140. [CrossRef]

35. Saito, T.; Kimura, S.; Nishiyama, Y.; Isogai, A. Cellulose nanofibers prepared by TEMPO-mediated oxidation of native cellulose. Biomacromolecules 2007, 8, 2485-2491. [CrossRef]

36. Fujisawa, S.; Saito, T.; Kimura, S.; Iwata, T.; Isogai, A. Surface engineering of ultrafine cellulose nanofibrils toward polymer nanocomposite materials. Biomacromolecules 2013, 14, 1541-1546. [CrossRef]

37. Truong, V.D.; Hu, Z.; Thompson, R.L.; Yencho, G.C.; Pecota, K.V. Pressurized liquid extraction and quantification of anthocyanins in purple-fleshed sweet potato genotypes. J. Food Compos. Anal. 2012, 26, 96-103. [CrossRef]

38. Wiczkowski, W.; Szawara-Nowak, D.; Topolska, J. Red cabbage anthocyanins: Profile, isolation, identification, and antioxidant activity. Food Res. Int. 2013, 51, 303-309. [CrossRef]

39. Wang, W.; Zhang, X.; Li, C.; Du, G.; Zhang, H.; Ni, Y. Using carboxylated cellulose nanofibers to enhance mechanical and barrier properties of collagen fiber film by electrostatic interaction. J. Sci. Food Agric. 2018, 98, 3089-3097. [CrossRef]

40. Lin, H.Y.; Tsai, J.C.; Lai, L.S. Effect of salts on the rheology of hydrocolloids from mulberry (Morus alba L.) leaves in concentrated domain. Food Hydrocoll. 2009, 23, 2331-2338. [CrossRef]

41. Haddarah, A.; Bassal, A.; Ismail, A.; Gaiani, C.; Ioannou, I.; Charbonnel, C.; Hamieh, T.; Ghoul, M. The structural characteristics and rheological properties of Lebanese locust bean gum. J. Food Eng. 2014, 120, 204-214. [CrossRef]

42. Long, Z.; Zhao, M.; Zhao, Q.; Yang, B.; Liu, L. Effect of homogenisation and storage time on surface and rheology properties of whipping cream. Food Chem. 2012, 13, 748-753. [CrossRef]

43. Wu, Y.; Ding, W.; Jia, L.; He, Q. The rheological properties of tara gum (Caesalpinia spinosa). Food Chem. 2015, 168, 366-371. [CrossRef] [PubMed]

44. Alam, M.N.; Islam, M.S.; Christopher, L.P. Sustainable Production of Cellulose-Based Hydrogels with Superb Absorbing Potential in Physiological Saline. ACS Omega 2019, 4, 9419-9426. [CrossRef]

45. Yuan, H.; Guo, X.; Xiao, T.; Ma, Q.; Wu, Y. Moisture adsorption in TEMPO-oxidized cellulose nanocrystal film at the nanogram level based on micro-FTIR spectroscopy. Cellulose 2019, 26, 7175-7183. [CrossRef]

46. Brar, V.; Kaur, G. Preparation and Characterization of Polyelectrolyte Complexes of Hibiscus esculentus (Okra) Gum and Chitosan. Int. J. Biomater. 2018, 2018, 4856287. [CrossRef] 
47. Wei, Y.C.; Cheng, C.H.; Ho, Y.C.; Tsai, M.L.; Mi, F.L. Active gellan gum/purple sweet potato composite films capable of monitoring pH variations. Food Hydrocoll. 2017, 69, 491-502. [CrossRef]

48. Bakkari, M.E.; Bindiganavile, V.; Goncalves, J.; Boluk, Y. Preparation of cellulose nanofibers by TEMPO-oxidation of bleached chemi-thermomechanical pulp for cement applications. Carbohydr. Polym. 2019, 203, 238-245. [CrossRef]

49. Martins, C.S.; Morgado, D.L.; Assis, O.B.G. Cashew gum-chitosan blended films: Spectral, mechanical and surface wetting evaluations. Macromol. Res. 2016, 24, 691-697. [CrossRef]

50. Fan, B.; Yao, Q.; Wang, C.; Jin, C.; Wang, H.; Xiong, Y.; Li, S.; Sun, Q. Natural cellulose nanofiber extracted from cell wall of bamboo leaf and its derived multifunctional aerogel. Polym. Compos. 2018, 39, 3869-3876. [CrossRef]

51. Li, J.; Hu, X.; Li, X.; Ma, Z. Effects of acetylation on the emulsifying properties of Artemisia sphaerocephala Krasch. polysaccharide. Carbohydr. Polym. 2016, 144, 531-540. [CrossRef] [PubMed]

52. Moloney, M.; Robbins, R.J.; Collins, T.M.; Kondo, T.; Yoshida, K.; Dangles, O. Red cabbage anthocyanins: The influence of d-glucose acylation by hydroxycinnamic acids on their structural transformations in acidic to mildly alkaline conditions and on the resulting color. Dyes Pigments 2018, 158, 342-352. [CrossRef]

53. Prietto, L.; Mirapalhete, T.C.; Pinto, V.Z.; Hoffmann, J.F.; Vanier, N.L.; Lim, L.T.; Guerra Dias, A.R.; da Rosa Zavareze, E. pH-sensitive films containing anthocyanins extracted from black bean seed coat and red cabbage. LWT Food Sci. Technol. 2017, 80, 492-500. [CrossRef]

54. Zhai, X.; Shi, J.; Zou, X.; Wang, S.; Jiang, C.; Zhang, J.; Huang, X.; Zhang, W.; Holmes, M. Novel colorimetric films based on starch/polyvinyl alcohol incorporated with roselle anthocyanins for fish freshness monitoring. Food Hydrocoll. 2017, 69, 308-317. [CrossRef]

(C) 2020 by the authors. Licensee MDPI, Basel, Switzerland. This article is an open access article distributed under the terms and conditions of the Creative Commons Attribution (CC BY) license (http://creativecommons.org/licenses/by/4.0/). 